\title{
Using Gap-Filling Radars in Mountainous Regions to Complement a National Radar Network: Improvements in Multiple-Doppler Wind Syntheses
}

\author{
JEFFREY BECK AND OLIVIER BOUSQUET \\ Météo-France, CNRM-GAME, Toulouse, France
}

(Manuscript received 20 July 2012, in final form 1 March 2013)

\begin{abstract}
The existing French Application Radar à la Météorologie Infrasynoptique (ARAMIS) operational radar network covers a vast majority of the country of France, yet like many national networks, gaps in coverage are present in regions of mountainous and high terrain. Many of these areas are prone to extreme, orographyinduced precipitation events, and therefore expansion of national radar networks into these regions is very important. The addition of small X-band radars, strategically placed to supplement the ARAMIS network, is discussed with emphasis on the ability to expand three-dimensional wind and reflectivity field retrieval. This expanded coverage is particularly important for terrain-related precipitation in the southern Alps. Successful dual- and multiple-Doppler syntheses were conducted using the existing ARAMIS network and two new radars located in mountainous terrain, installed within the context of the Risques Hydrométéorologiques en Territoires de Montagnes et Mediterranéens (RHYTMME) program. To illustrate the coverage and advantage that gap-filling radars can add to an existing national radar network, two case studies are presented, with multiple-Doppler syntheses revealing that terrain relief and low-level atmospheric stability influence the resulting wind field. In addition to the added coverage, the RHYTMME gap-filling radars improve wind-flow retrieval and the accuracy of reflectivity measurements over extreme southeast France and into the Mediterranean Sea.
\end{abstract}

\section{Introduction}

Regional and national operational radar networks are a crucial component in short-term forecasting and are a key source for the detection of hazardous meteorological phenomena. In addition, their data, including radial velocity and reflectivity, are now being assimilated within high-resolution numerical models to provide additional observational information previously unavailable within the traditional, ground-based observing network (Montmerle and Faccani 2009; Caumont et al. 2010). Given their importance to weather forecasting and public safety, the ability to obtain sufficient radar coverage over large regions, mountainous terrain, and significant population centers is essential, but many times difficult to achieve.

For example, within the U.S. national Next Generation Weather Radar network (NEXRAD; Maddox et al.

\footnotetext{
Corresponding author address: Jeffrey R. Beck, Météo-France/ Centre National de Recherches Météorologiques, 42 Ave. G. Coriolis, 31057 Toulouse, CEDEX 1, France.

E-mail: jeff.beck@meteo.fr
}

2002), radars are placed approximately $200-300 \mathrm{~km}$ apart. This spacing presents a troubling radar coverage problem, where both distance between radars and earth curvature impact the ability of the radars to scan low altitudes at far distances. These gaps in radar coverage are significant in the sense that they limit the ability to detect meteorological phenomena affecting low levels. The Collaborate Adaptive Sensing of the Atmosphere (CASA) project was created in an attempt to mitigate this problem through lower-cost X-band radars (relative to C- and S-band systems) spaced at distances of less than $30 \mathrm{~km}$ (McLaughlin et al. 2009). An initial network of four $\mathrm{X}$-band radars was set up in central Oklahoma as a test bed for this project (Philips et al. 2010), where severe thunderstorms and tornadoes frequently occur. Preliminary results show that this type of network improves low-level coverage, resolution, and detection of severe-weather events, when compared with the standard, national radar network.

On a smaller scale, France's national Application Radar à la Météorologie Infrasynoptique (ARAMIS) radar network contains a total of 24 radars ( $8 \mathrm{~S}$ band and $16 \mathrm{C}$ band; Fig. 1), many of which have dual-polarization technology. When considering the areal coverage of volumetric scans, 


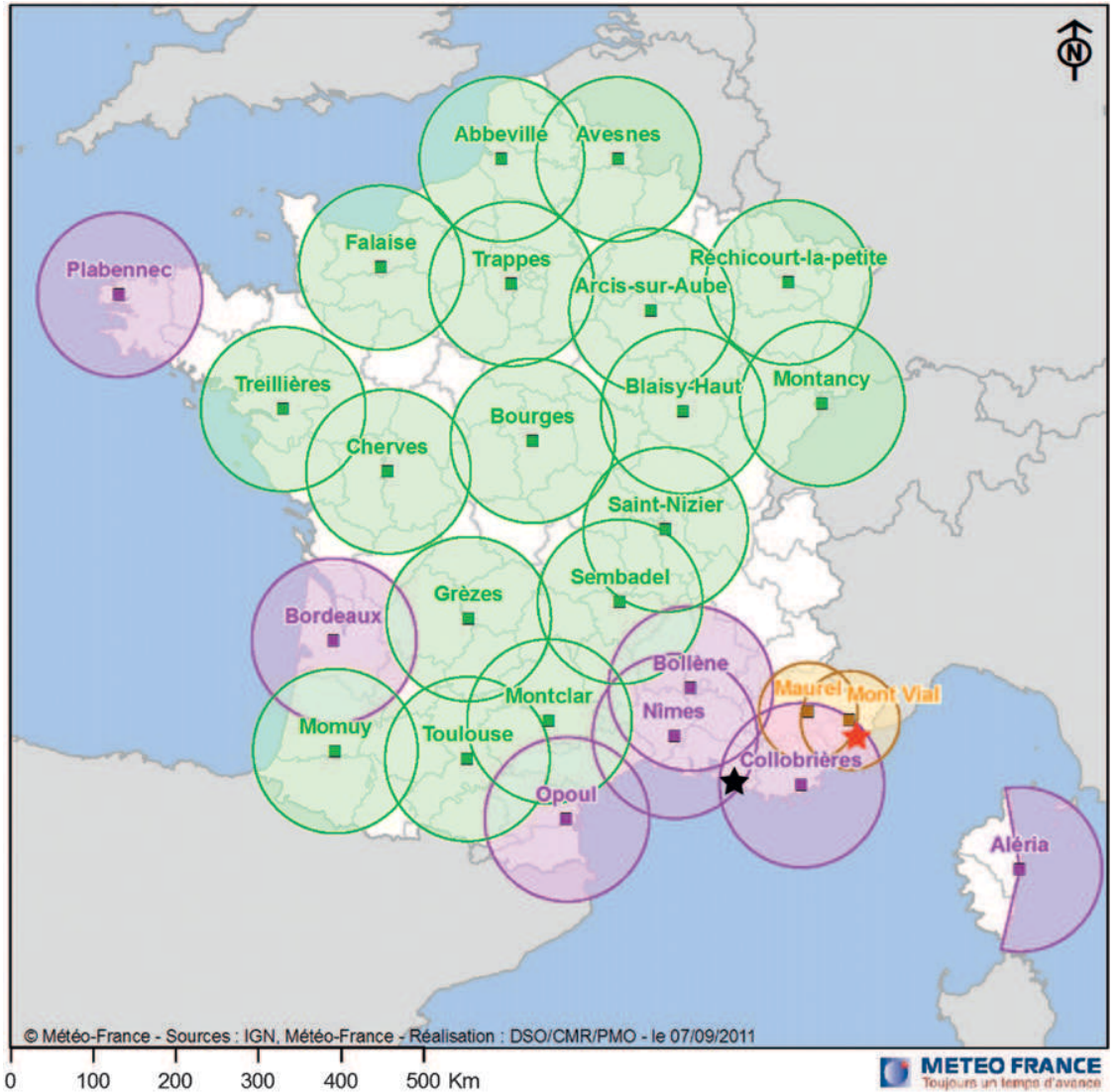

FIG. 1. Map of the French radar network, showing C-and S-band radars in green and purple, respectively, with RHYTMME radars shown in brown. The locations of Marseille and Nice are shown with black and red stars, respectively.

this network reaches over $90 \%$ of France, making it one of the densest national radar networks in the world. However, regions still exist where radar coverage is lacking (Fig. 2a), particularly in the complex terrain of southeast France, where the risk of high-precipitation events and potential flash flooding is enhanced by the southern Alps.

Mountains, especially those located near the sea, can facilitate the formation of extremely intense rainfall on relatively localized scales. For particularly sensitive watersheds, strong precipitation events can generate rapid and destructive floods, presenting a major threat to life and property, especially given growing urbanization and a concentration of population during the last few decades in flood-prone areas. For these reasons, the influence of mountainous topography on moist dynamics and cloud microphysics has received considerable attention in the last few years, giving rise to several field and research programs such as the Mesoscale Alpine Programme (MAP; Bougeault et al. 2001), the Improvement of Microphysical Parameterization through Observational Verification Experiment (IMPROVE; Stoelinga et al. 2003), the Intermountain Precipitation
Experiment (IPEX; Schultz et al. 2002), and the Hydrological Cycle in the Mediterranean Experiment (HyMeX; see online at http://www.hymex.org/). These field programs were designed to improve the understanding and prediction of orographically generated precipitation. The analysis of datasets from these field campaigns yielded important results concerning moist dynamics and microphysics over complex terrain (e.g., Medina et al. 2005; Rotunno and Houze 2007); however, predicting the intensity, location, and duration of orographically induced precipitation nevertheless remains a major scientific challenge. In particular, based on the work of Schultz et al. (2002), improvements to precipitation forecasts in mountainous regions requires better 1) observations; 2) understanding of cloud, storm, and precipitation processes; and 3 ) numerical weather prediction (NWP), particularly model physics.

Focusing on the interaction of synoptic systems with the mountainous regions of Lago Maggiore in northwest Italy, Medina and Houze (2003) found that onshore wind flow perpendicular to the axis of the mountains in relation to the low-level stability plays a key role in how 
(a)

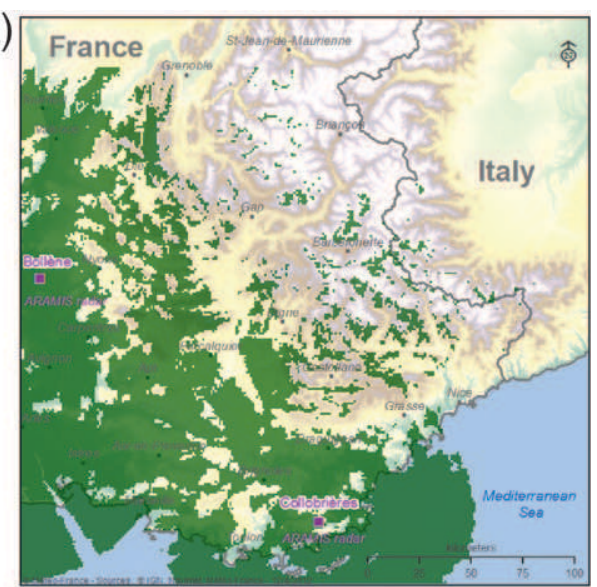

(b)

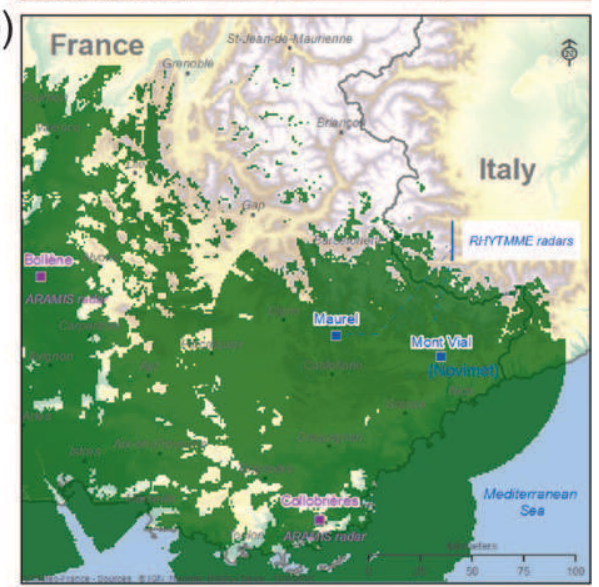

(c)

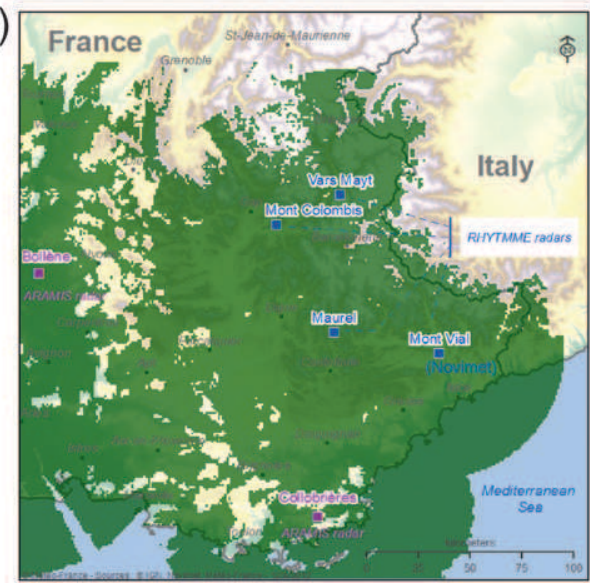

FIG. 2. Volumetric radar coverage (in green) including beam blockage from topography for southeast France, showing (a) regions covered by the current ARAMIS radar network, (b) coverage with the addition of the Mont Vial and Mont Maurel RHYTMME radars, and (c) the future coverage with all RHYTMME radars.

precipitation forms as onshore airflow encounters the Alps. The authors calculated the Froude number in two cases studied from data collected during MAP to analyze low-level stability. Defined as $V /(N L)$ (Glickman 2000), the Froude number indicates whether a given air mass will be blocked by a $2 \mathrm{D}$ mountain or obstacle, where $V$ is the upstream flow speed perpendicular to the terrain, $N$ is the Brunt-Väisälä frequency, and $L$ is the height of the blocking terrain (note that in this paper, the moist Froude number is used, as defined later). Froude numbers greater than 1 indicate unblocked flow where air is able to ascend the terrain, while numbers less than 1 indicate blocked flow. Medina and Houze (2003) found that with a Froude number less than 1, precipitation over the mountains was not as strong as in the unblocked case, since some of the airflow was obstructed and did not rise. However, in an unstable air mass with a Froude number greater than 1, low-level flow was able to ascend the mountains, generating greater precipitation amounts over the terrain.

Panziera and Germann (2010) conducted an investigation of 58 orography induced precipitation events in the southern Alps. Their results show that low-level airmass instability played a role in the generation of precipitation, but to a lesser extent than the direction and speed of the onshore flow. The authors showed that the impinging wind direction impacted the location and distribution of the heaviest precipitation and that wind speed intensity played a major role in the observed precipitation rate. Results from this study indicate the kinematic parameters of the upstream airflow to be the most important factor in producing terrain-induced precipitation. Knowledge of the offshore wind flow southeast of France is therefore central to understanding how orography induced precipitation will affect the heavily populated French coastline.

These findings outline the need for additional and denser three-dimensional observations within and upstream of complex terrain. Successful operation of radars within mountainous regions, such as the MeteoSwiss network (Germann et al. 2006), and small, portable X-band radars (Gabella et al. 2012) indicate the possibility to reliably collect data in these areas. Therefore, within preexisting networks, one possibility exists to implement dual-polarization, gap-filling X-band radars to fulfill the goal of enhanced data collection in previously inaccessible regions. For example, the X-NET project (Maki et al. 2010) was created to form a dense, dual-polarization, $\mathrm{X}$-band radar network throughout a large portion of Japan, complementing preexisting C-band radars. Together, $26 \mathrm{X}$-band radars have been installed near highly populated regions of Japan, including portions of the country with extreme changes in terrain. In addition to covering gaps in the existing radar network, polarimetric variables collected by the radars provide greatly improved quantitative precipitation estimation (QPE) relative to that generated by the traditional singlepolarization radar network. 
A similar project, the Risques Hydrométéorologiques en Territoires de Montagnes et Mediterranéens (RHYTMME), was developed to mitigate coverage gaps in the French ARAMIS radar network and to improve the ability to forecast and study localized, high-risk precipitation events in the southern French Alps (Westrelin et al. 2012). At present, two RHYTMME radars are operational, at Mont Vial and Mont Maurel, providing coverage for the maritime French Alps (Fig. 2b). Installed in 2010, the radar on Mont Vial is a Novimet, Hydrix $\mathrm{X}$-band radar owned by the Centre National de la Recherche Scientifique (CNRS). The Mont Maurel radar, installed in 2011, is a Selex-Gematronik X-band radar owned and managed by Météo-France, and represents the second RHYTMME radar.

Eventually, a total of four RHYTMME, X-band, dualpolarization radars will be deployed in the Alpine region of southeast France (Fig. 2c) to improve coverage and radar products in the region. The Mont Colombis radar will be the third radar to be installed (in 2013) with the final radar at Vars Mayt, expected in 2014. In the future, the possibility exists to expand the RHYTMME network to the northern Alps, toward Grenoble, France (2015), as well as to other mountainous regions such as the Pyrenees or the Massif Central, where other gaps in radar coverage can also be diminished.

In addition to better QPE, hydrometeor classification, and radial velocity, the availability of increased radar coverage can improve the verification of model forecast output through comparison with multiple-Doppler wind field syntheses. With the implementation of a triple-pulse repetition time (PRT) scheme (Tabary et al. 2006) for the French ARAMIS radar network, Bousquet et al. (2007, 2008b) showed that mitigation of the "Doppler dilemma" allowed for long-range data collection, with a high $\mathrm{Ny}$ quist velocity, dramatically reducing contamination of data with velocity aliasing. Given this potent addition to the French radar network, real-time wind-field syntheses were possible over a large region of northern France (Bousquet el al. 2007) and subsequent analysis revealed that accurate retrieval of three-dimensional wind fields was possible within differing scales of meteorological phenomena, including an occluded frontal system and squall line with associated bow echo (Bousquet et al. 2008b). Following these analyses, Bousquet et al. (2008a) provided evidence that wind field syntheses can be used to compare the timing and placement of synoptic fronts with output from high-resolution model data. In addition, quantitative comparisons of wind speed and direction were made through error calculation, including bias and RMS, between the retrieved multiple-Doppler wind field and model data, allowing for verification of mesoscale features found in the model output. More recently, an extended version of this analysis allowing for wind-field retrieval over continental France was proposed by Bousquet and Tabary (2013).

The use of real-time, multiple-Doppler synthesis data could provide future potential in the field of nowcasting, especially with expanded radar coverage in mountainous terrain. Extrapolation nowcasting methods, such as those used by Dixon and Wiener (1993), including forecasts of thunderstorm size, position. and intensity [or those with more advanced advection schemes, such as in Germann and Zawadzki (2002)] could be improved with the addition of wind vector synthesis data. Shortterm storm forecasting could benefit especially from wind field information surrounding and downstream of the thunderstorm. In particular, multiple-Doppler wind fields could complement existing nowcasting schemes in mountainous terrain, where persistence advection schemes may not perform as well as in open terrain. For example, analog nowcasting techniques such as those used by Panziera et al. (2011), specifically for mountainous regions, could be coupled with three-dimensional wind field data. Given the small time-scale variability that can accompany precipitation in high terrain, the addition of these data to analog techniques may prove highly beneficial.

Given the precedence for accurate multiple-Doppler retrieval within the ARAMIS network domain, data were combined from the ARAMIS and RHYTMME radar networks to compute real-time, three-dimensional, multiple-Doppler wind syntheses in regions that were previously inaccessible by the traditional S- and C-band ARAMIS radars. These syntheses reveal the advantage that gap-filling radars can provide above and upstream of mountainous terrain when combined with a preexisting traditional radar network. From these data, two case studies were selected and further analyzed to illustrate how these gap-filling radars can improve the understanding of onshore flow in extreme southeastern France.

\section{Methodology}

The radars in the ARAMIS network collect radial velocity, reflectivity, and (depending on the radar) a suite of dual-polarimetric variables every $15 \mathrm{~min}$ at elevations ranging from $0.5^{\circ}$ to $60^{\circ}$. A triple-PRT scheme is used (Tabary et al.2006) allowing for an unambiguous Nyquist velocity of $60 \mathrm{~m} \mathrm{~s}^{-1}$. Dual-polarimetric variables are collected and used in a fuzzy logic algorithm (Gourley et al. 2007) to separate nonprecipitating from precipitating echoes. This information is then used to filter the radar data of ground clutter, second trip, and other anomalous returns, in order to prepare the data for multiple-Doppler retrieval. The reader is referred to Bousquet et al. 
TABLE 1. Mont Vial scanning characteristics.

\begin{tabular}{lc}
\hline \multicolumn{1}{c}{ Location } & $43.895^{\circ} \mathrm{N}, 7.153^{\circ} \mathrm{E}$ \\
\hline Elev (m MSL) & 1525 \\
Beamwidth $\left(^{\circ}\right)$ & 1.5 \\
Frequency $(\mathrm{MHz})$ & 9375 \\
Dual-PRF volume scan & 15 \\
$\quad$ repetition frequency (min) & \\
Elev $\left({ }^{\circ}\right)$ & $-1.0,0.4,1.2,2.4,4,17,30$, and 60 \\
PRF $(\mathrm{Hz})$ & 800 and 1000 \\
Nyquist velocity $\left(\mathrm{m} \mathrm{s}^{-1}\right)$ & 24 \\
\hline
\end{tabular}

(2008a,b) for more details about ARAMIS radar data preprocessing.

The processing algorithm used by the ARAMIS radar network was adapted to the RHYTMME X-band radars, and successfully implemented to allow for automated editing and filtering of erroneous and other anomalous radar data. Specifically, the dual-polarimetric variables are collected, followed by an attenuation correction for horizontal and differential reflectivity, given that the RHYTMME radars operate at $\mathrm{X}$ band. Conducted on a gate-to-gate basis for both horizontal reflectivity $Z_{H}$ and differential reflectivity $Z_{\mathrm{DP}}$, the attenuation correction consists of a proportionality constant (for $\mathrm{X}$ band, $\gamma_{H}=0.28$ and $\left.\gamma_{\mathrm{DP}}=0.04\right)$ multiplied by the differential phase $\Phi_{\mathrm{DP}}$. This sum is then added to the respective reflectivities. After attenuation correction, the signal-to-noise ratio (SNR) is calculated and echo type is differentiated using the fuzzy logic algorithm with probability density function (PDF) curves for precipitating and specific, nonprecipitating (insects, birds, ground) echoes. This algorithm utilizes horizontal reflectivity $Z_{H}$, the correlation coefficient $\rho_{\mathrm{HV}}$, the spectrum width $\sigma_{v}$, the SNR, the texture of the differential reflectivity $Z_{\mathrm{DR}}$, and knowledge of the melting-layer height (derived from both radar and model data) with the PDF curves to determine echo type (Al-Sakka et al. 2012).

However, noise and other errors are produced by the dual-PRF scheme used by Mont Vial and the triple-PRT scheme used by Mont Maurel, in part due to small ratios between PRF values (e.g., Jorgensen et al. 2000; Augros and Tabary 2009), and require a median filter and further editing to ensure that the data are error free. Application of median filters to remove erroneous radial velocity data from radars using dual-PRF and triple-PRT schemes has been successfully implemented in the past (Tabary et al. 2006; Bousquet el al. 2008b; Montmerle and Faccani 2009). It is this combination of dual-polarimetric hydrometeor classification and median filter editing that allows for realtime dual- and multiple-Doppler synthesis retrieval.

The scanning strategies of the Mont Vial and Mont Maurel radars used in the multiple-Doppler syntheses
TABLE 2. Mont Maurel scanning characteristics.

\begin{tabular}{lc}
\hline \multicolumn{1}{c}{ Location } & $44.013^{\circ} \mathrm{N}, 6.529^{\circ} \mathrm{E}$ \\
\hline Elev (m MSL) & 1773 \\
Beamwidth $\left(^{\circ}\right)$ & 1.35 \\
Frequency $(\mathrm{MHz})$ & 9375 \\
Dual-PRF volume scan & 5 \\
$\quad$ repetition frequency (min) & \\
Elev $\left({ }^{\circ}\right)$ & $0.5,1.5,2.7,4.0$, and 5.5 \\
PRF $(\mathrm{Hz})$ & 438,467, and 500 \\
Nyquist velocity $\left(\mathrm{m} \mathrm{s}^{-1}\right)$ & 56 \\
\hline
\end{tabular}

are shown in Tables 1 and 2, respectively, indicating the dual-PRF and triple-PRT schemes used. Mont Vial records dual-PRF volume scans every $15 \mathrm{~min}$, whereas Mont Maurel completes volume scans every $5 \mathrm{~min}$, allowing for accurate time calibration of the datasets with the ARAMIS radars for multiple-Doppler syntheses.

The Mont Vial radar is located approximately $20 \mathrm{~km}$ north of the city of Nice, France, while Mont Maurel is situated $52 \mathrm{~km}$ west-northwest of Mount Vial (Fig. 1). Both radars are located between 1500 and $1800 \mathrm{~m}$ above mean sea level (MSL) and are placed in a location inaccessible at low altitudes by the current ARAMIS network. The nearest ARAMIS radars are Collobrieres, Nimes, and Bollene (Fig. 1). These three ARAMIS radars were used in the multiple-Doppler syntheses with Mont Vial and Mont Maurel. Initially, only the ARAMIS radars were used to construct a three-dimensional wind field during a particular case study. Afterward, Mont Vial and Mont Maurel data were added to the syntheses to visualize the advantage of gap-filling radars.

Prior to any multiple-Doppler retrievals, fixed-height coverage maps were generated to show the potential multiple-Doppler retrieval region with and without Mont Vial and Mont Maurel at specific vertical levels. At $2.5 \mathrm{~km}$ MSL, the fixed-height coverage for the three ARAMIS radars is shown (Fig. 3a). Dual- and multipleDoppler coverage is already extensive over a large portion of the domain. However, with the addition of Mont Vial (Fig. 3b) and Mont Maurel (Fig. 3c), the coverage at $2.5 \mathrm{~km}$ MSL is expanded with dual- and multiple-Doppler coverage extending well into the Mediterranean Sea, and overdetermined Doppler coverage increasing over much of the region.

To conduct the multiple-Doppler syntheses, unfolded, edited radial velocity data were first converted from polar to Cartesian coordinates using a Cressman interpolation scheme (Cressman 1959), after which the radial velocities existing at each available grid point were used to generate horizontal and vertical wind components. The process of data interpolation and wind synthesis was carried out using the multiple-Doppler synthesis and continuity 
(a)

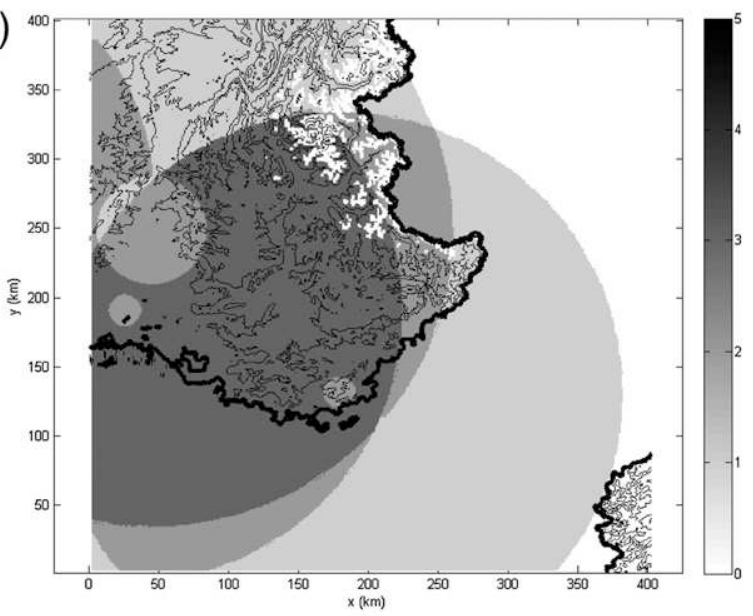

(b)

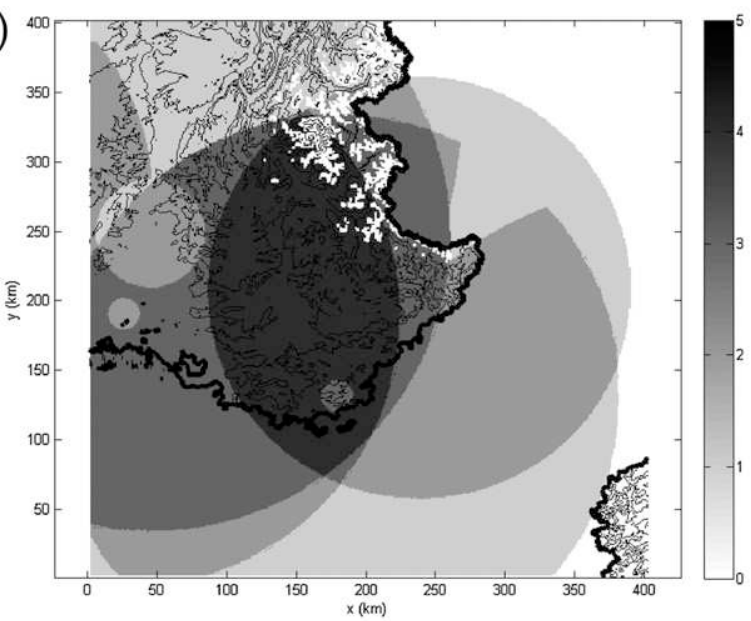

(c)

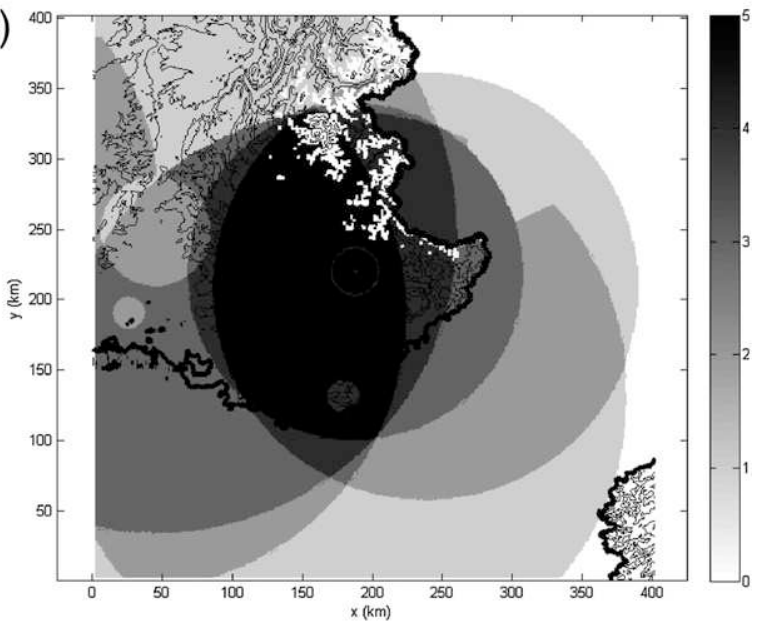

FIG. 3. Fixed-height single- and multiple-Doppler coverage maps for southeast France at $2.5 \mathrm{~km}$ MSL with the number of radars covering an area depicted by the shading. Coverage is shown with (a) only ARAMIS radars, (b) the addition of Mont Vial, and (c) the addition of both Mont Vial and Mont Maurel radars. adjustment technique (MUSCAT) software suite (Bousquet and Chong 1998). Specifically, MUSCAT was used to retrieve three-dimensional wind vectors at intervals of $1 \mathrm{~km}$ horizontally and $500 \mathrm{~m}$ vertically. The radius of influence used in the Cartesian interpolation was $2 \mathrm{~km}$ in the horizontal and $1 \mathrm{~km}$ in the vertical.

The two events chosen for analysis provide evidence of important additional coverage from the RHYTMME radars, and illustrate contrasting low-level wind regimes, allowing for a unique opportunity to assess onshore flow. The first case occurred prior to Mont Maurel data availability, between the evening of 24 October 2011 and the early morning hours of 25 October 2011, when a strong synoptic system affected southeast France (Fig. 4a). Precipitation amounts of up to $150 \mathrm{~mm}$ occurred during this event along the Mediterranean coast near both Marseille and Nice, as well as near the Mont Vial radar. The scope of the precipitation was extremely broad and provided an excellent opportunity to assess radar coverage. In particular, three volumes were chosen to show the evolution of this synoptic system and the impact of Mont Vial: 0130, 0230, and 0400 UTC. The time periods chosen show the eastward advancement of the system across the radar network, and the increasing coverage available given the addition of the Mont Vial radar.

The second precipitation event chosen for analysis occurred on 20 May 2012 and allowed for assessment of both Mont Maurel and Mont Vial on the multipleDoppler syntheses (Fig. 4b). Up to $100 \mathrm{~mm}$ of rain fell over southeastern France, as a weak upper-level, cutoff low generated regions of precipitation across parts of France. However, onshore flow in southeast France enabled localized convective precipitation to form adjacent to, and over, the southern Alps. Therefore, three time periods $(2100,2200$, and 2300 UTC) were chosen to show the evolution of the wind field as the precipitation propagated through the radar network.

\section{Analysis \\ a. Coverage}

A quantitative assessment was first conducted to calculate the added coverage the RHYTMME radars provide. Increases in coverage were computed for the total volumetric area scanned by the radars (up to $12 \mathrm{~km}$ MSL), delineating between single- and multiple-Doppler coverage. When adding Mont Vial and Mont Maurel to the ARAMIS network, single-Doppler volumetric coverage increases by $8 \%\left(122086 \mathrm{~km}^{2}\right)$ within the domain specified in Fig. 3. Because of a large maximum unambiguous range incorporated by the S- and C-band ARAMIS radars, this increase in coverage generally occurs at low levels over high terrain near the RHYTMME 

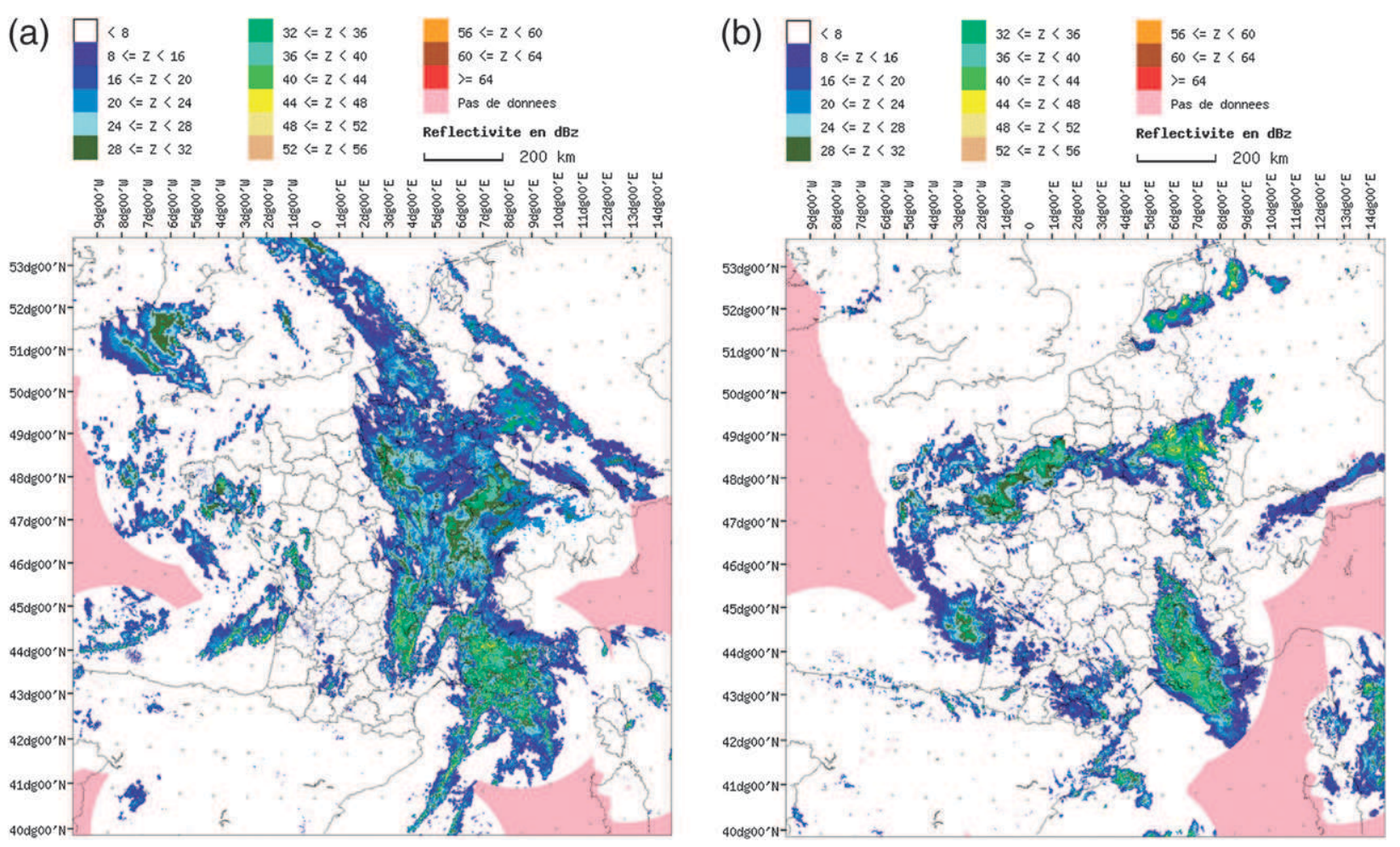

FIG. 4. French ARAMIS mosaic reflectivity images for (a) 25 Oct 2011 and (b) 31 Jan 2012.

radars, a valuable region for additional total volumetric coverage in the domain.

However, a major increase is shown when assessing the increase in multiple-Doppler coverage. Dual- and overdetermined-Doppler coverage increases by $34 \%$ $\left(318166 \mathrm{~km}^{2}\right)$, representing an additional one-third of the three-dimensional domain specified. It is this latter increase in multiple-Doppler coverage that allows for wind-flow retrieval over a much broader region, as well as an improvement in the accuracy and resolution of these analyses due to the combination of the ARAMIS network with the additional RHYTMME radars.

\section{b. Mesoscale environments and radar observations for 25 October 2011 and 20 May 2012}

Precipitation associated with the synoptic system of 25 October 2011 began to traverse the Rhone River valley at 0130 UTC; however, strong reflectivity had not yet reached the extreme southeastern portions of France. Assessing a sample altitude of $1.5 \mathrm{~km}$ MSL, coverage in previously inaccessible regions by the ARAMIS radars (Fig. 5a) is improved by the addition of Mont Vial (Fig. 5b) providing extra reflectivity and some two-dimensional wind vectors. As the synoptic system progressed eastward, by 0230 UTC, the availability of the Mont Vial radar presents a clear advantage to the multiple-Doppler radar syntheses (cf. Figs. 5c and 5d). The ARAMIS radars are still incapable of retrieving reflectivity in southeast France but the network is insufficient to allow the determination of multiple-Doppler wind vectors over the mountainous terrain. However, the Mont Vial provides additional reflectivity at $1.5 \mathrm{~km}$ MSL over a broad region as well as the ability to retrieve additional wind vectors over southeast France, the southern Alps, and the Mediterranean Sea (Figs. 5d and 5f).

At $3 \mathrm{~km}$ MSL (Fig. 6), wind vectors off the coast of France during the 25 October 2011 case show broad southwesterly flow south of Marseille and Nice, while winds back toward more southerly flow off the coast of extreme southeast France (Figs. 6b,d,f). None of this information is available using only the ARAMIS radar network (Figs. 6a,c,e). In addition, a slight transition of the wind is seen as it encounters the terrain of the southern Alps (especially south of Marseille at 0230 and 0400 UTC on 25 October 2011, where winds back as they come onshore). Yet, overall, the onshore flow remains uniform in strength and direction crossing the mountains from south to north both at 1.5 and $3.0 \mathrm{~km} \mathrm{MSL}$ (Figs. 5 and 6, respectively).

Given the strong precipitation created during this event, Fig. 6 shows the importance that the Mont Vial radar has for estimating the strength of precipitation over southeast France. Using only the ARAMIS radars, reflectivity at $3 \mathrm{~km}$ MSL over the southern Alps 
(a)

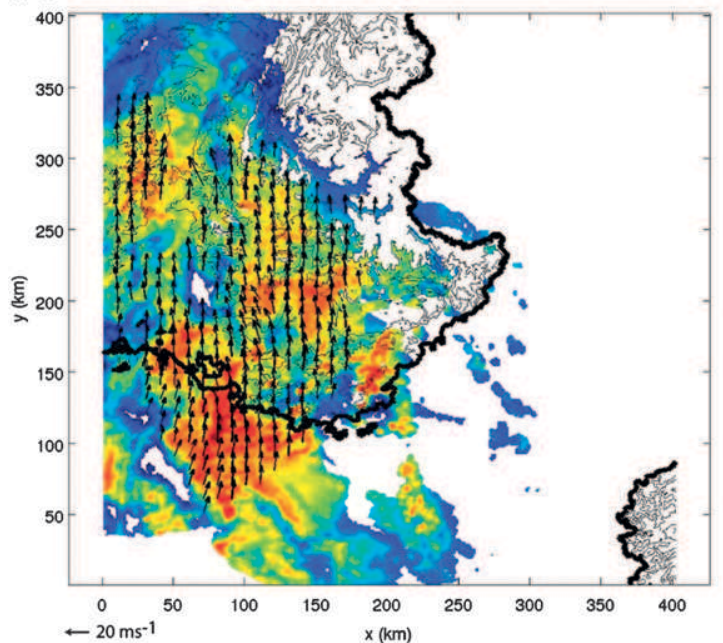

(c)

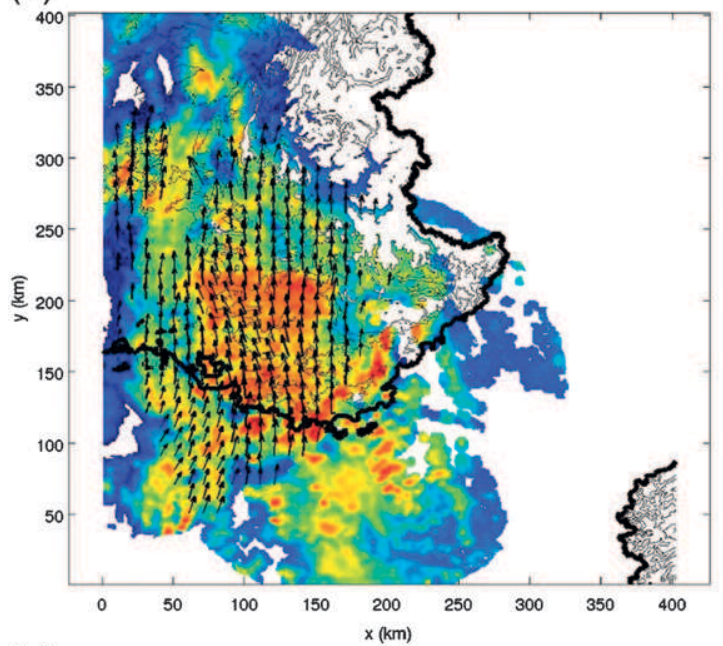

(e)

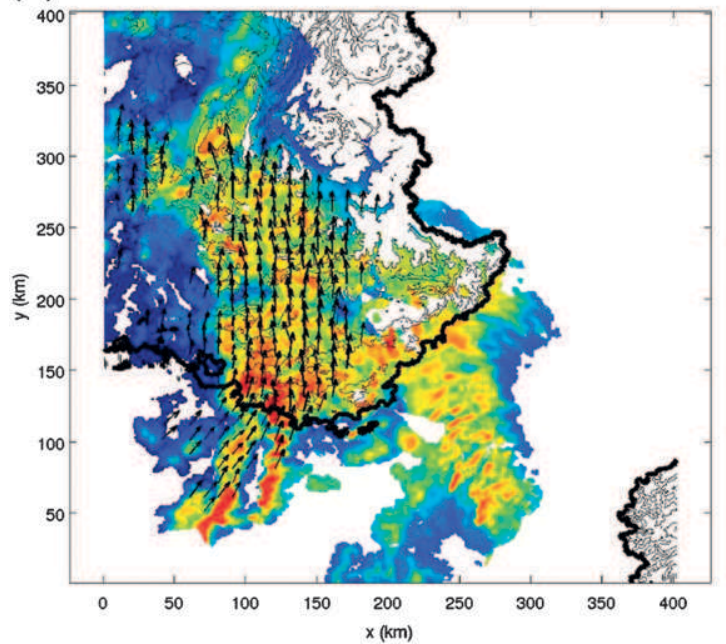

(b)
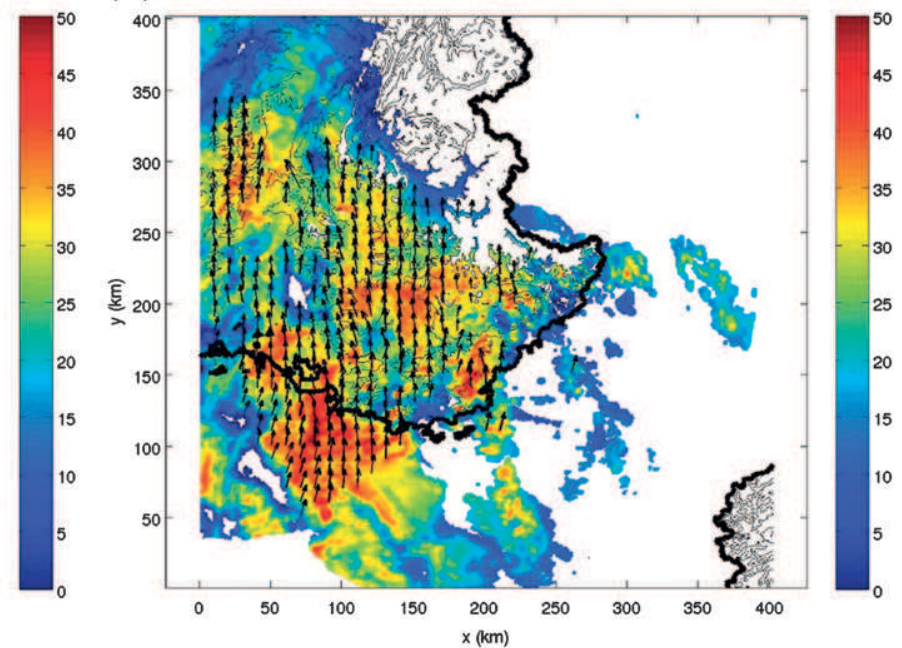

(d)
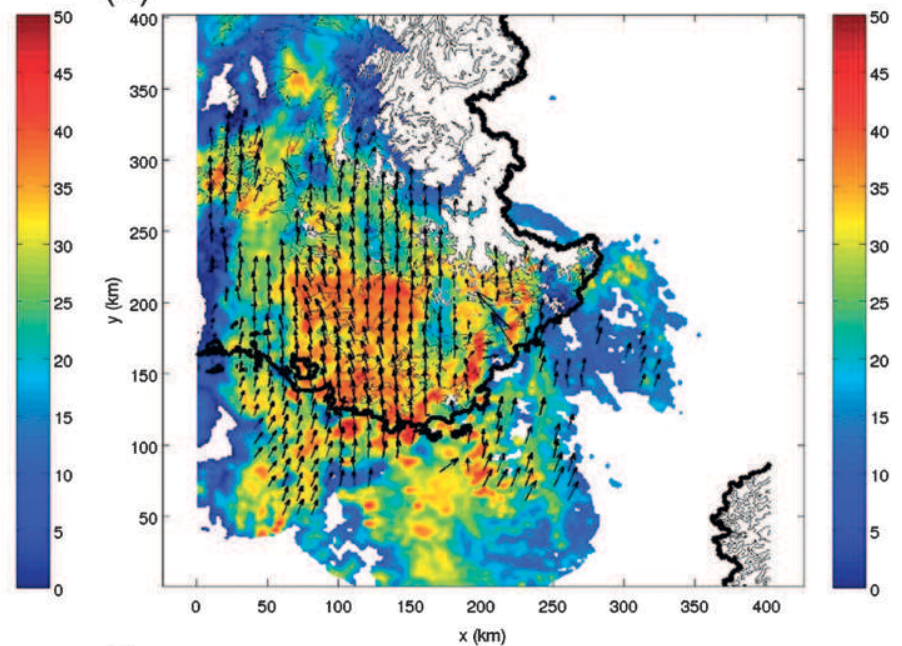

(f)
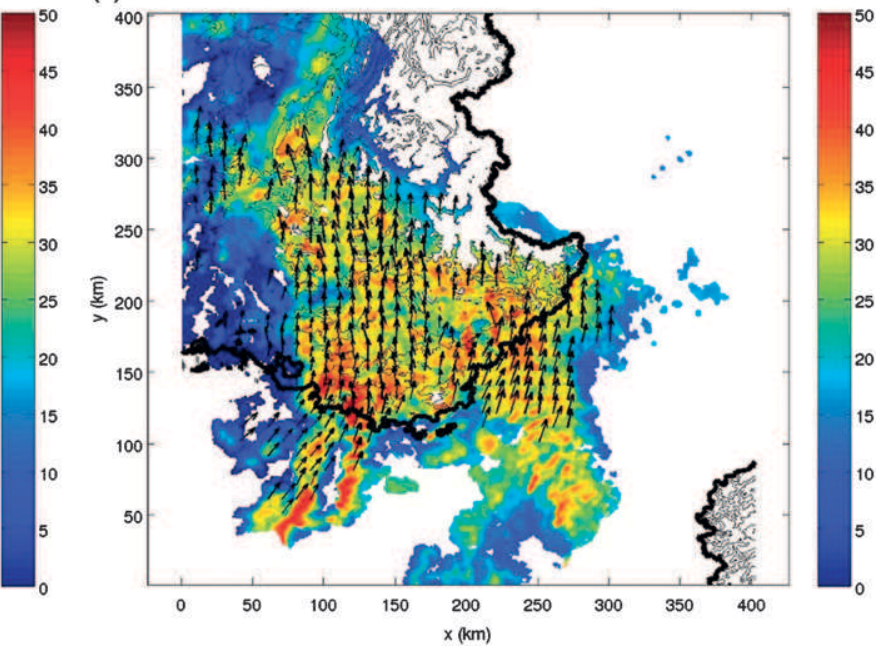

FIG. 5. Multiple-Doppler syntheses for 25 Oct 2011 at (a),(b) 0130, (c),(d) 0230, and (e),(f) 0400 UTC for $1.5 \mathrm{~km}$ MSL showing 2D wind vectors (black; every 10th vector is shown), reflectivity (color; dBZ), and terrain contours (gray): (left) the three ARAMIS radars and (right) with the addition of the Mont Vial radar. 
(a)

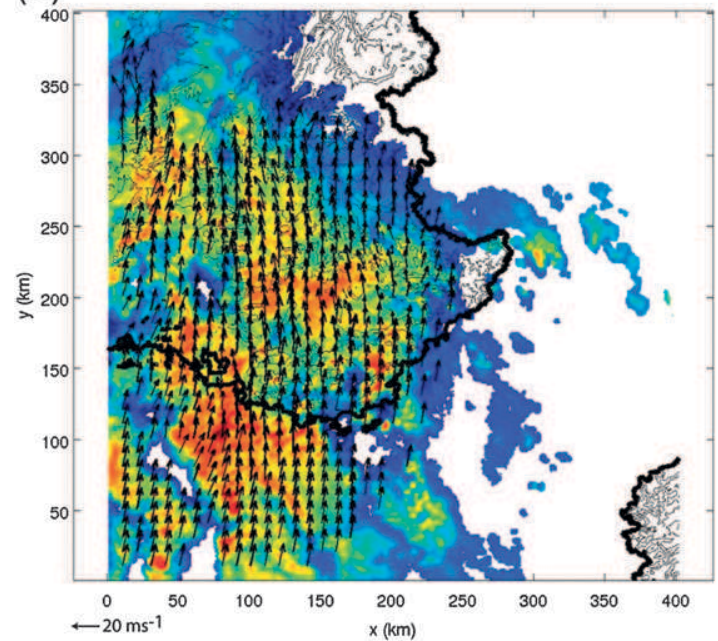

(c)

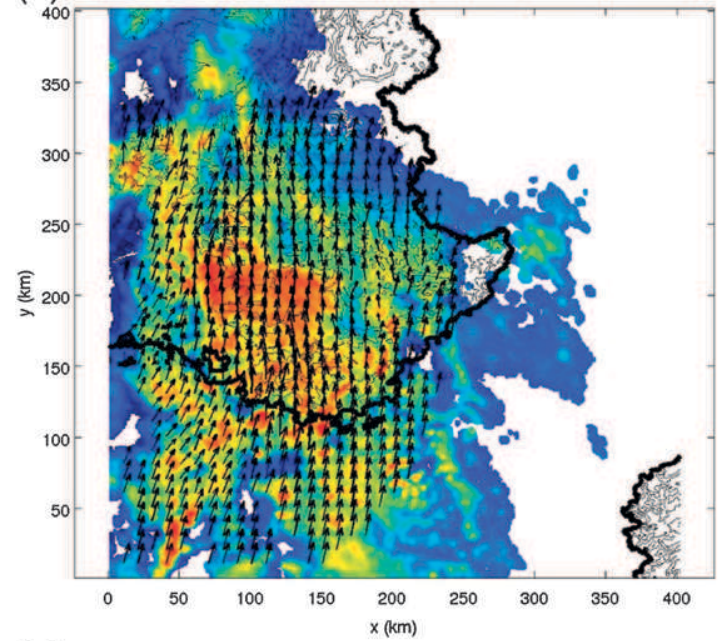

(e)

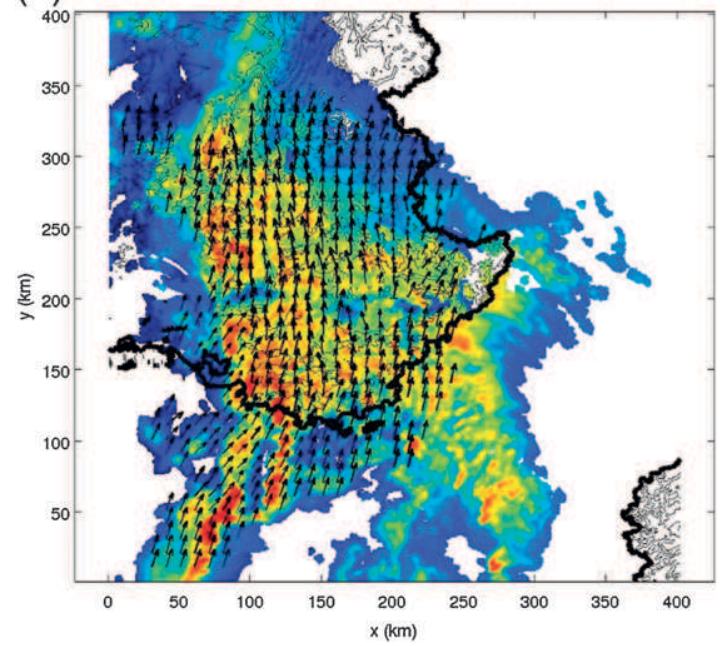

(b)
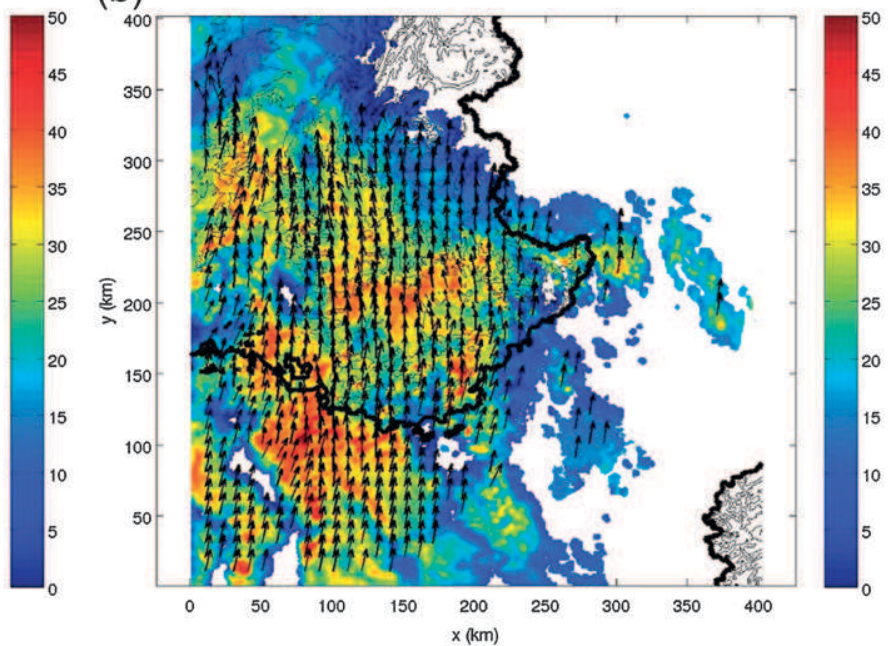

(d)
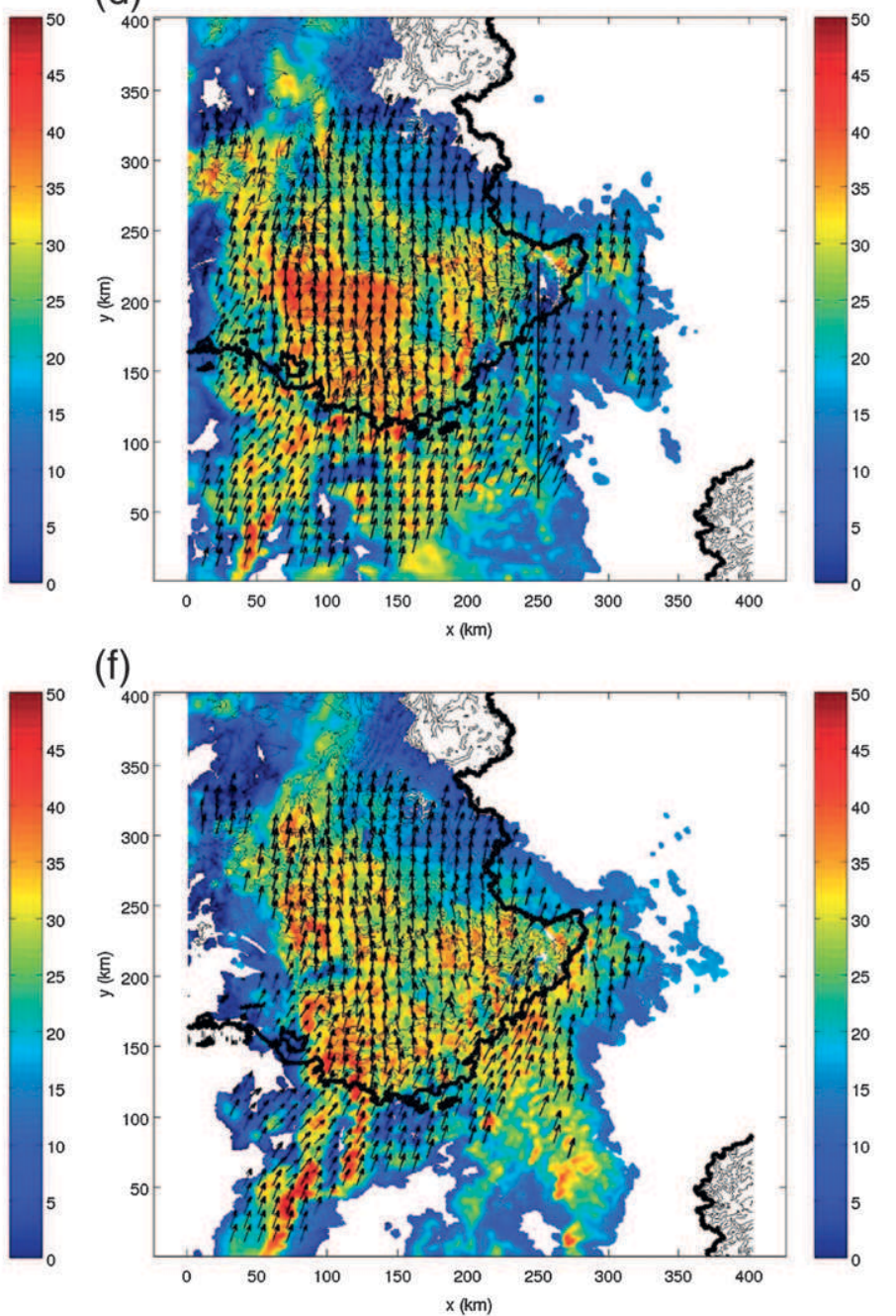

(f)

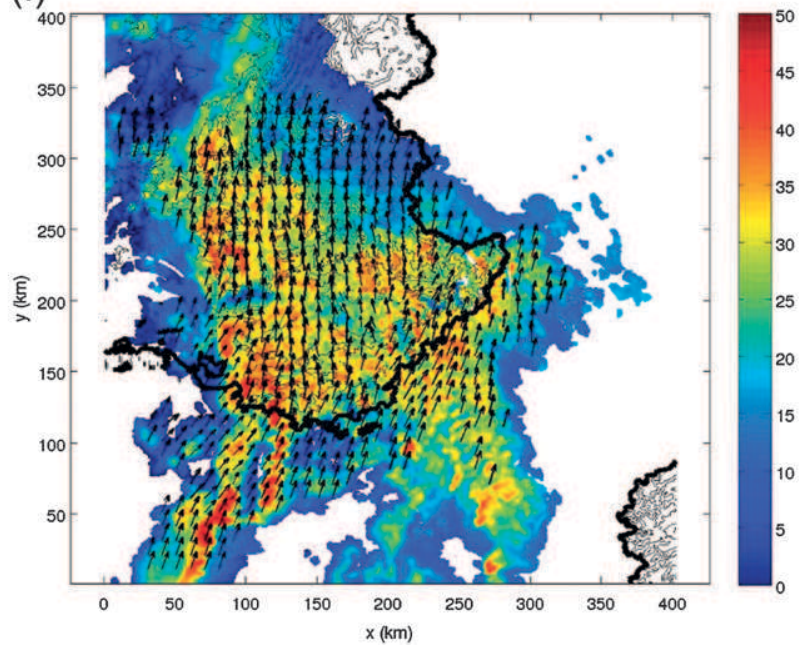

Fig. 6. As in Fig. 5, but for an altitude of $3 \mathrm{~km}$ MSL. Straight black vertical line in (d) indicates location of Fig. 7. 
(a)

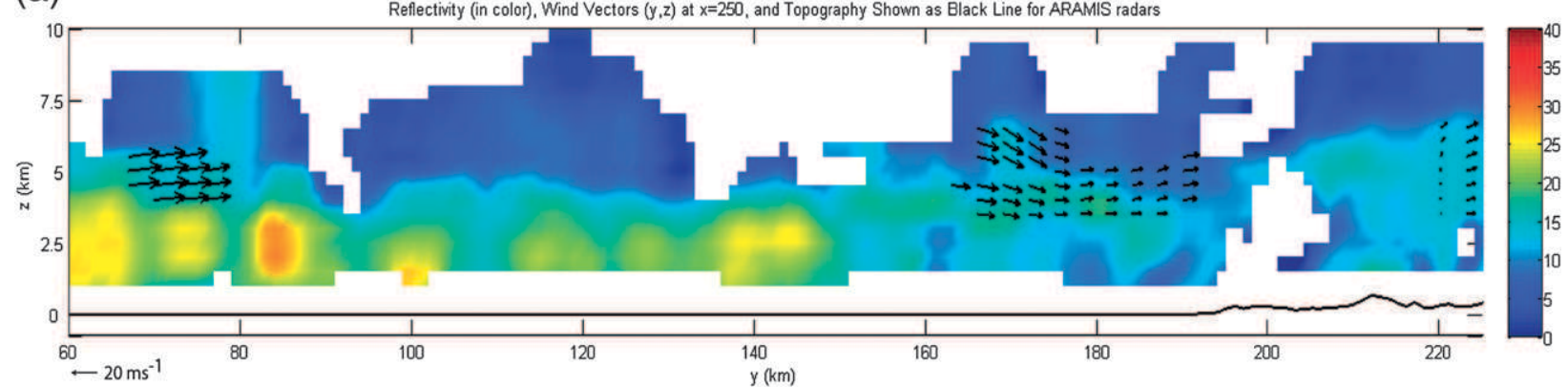

(b)

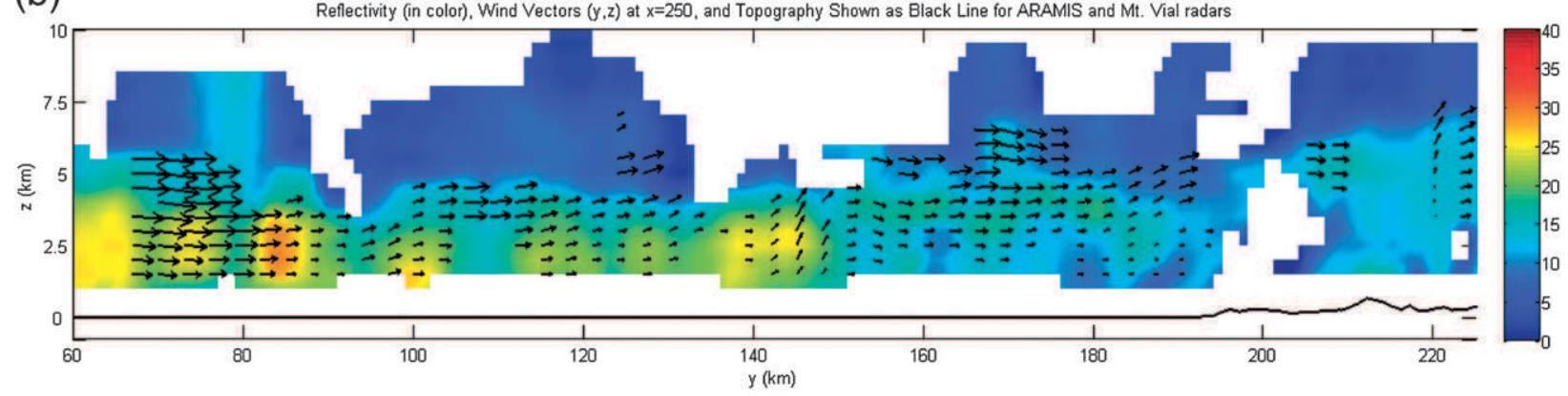

FIG. 7. (a) ARAMIS and (b) ARAMIS plus RHYTMME multiple-Doppler synthesis ( $y, z$ wind vectors; every 10 th shown) for 25 Oct 2011 at 0230 UTC for $x=250$ in Fig. 6d. Reflectivity (dBZ) is shown in color and topography as a black solid line.

(northwest of Nice) is underestimated, showing regions of reflectivity between 20 and $30 \mathrm{~dB} Z$, whereas the values are between approximately 30 and $40 \mathrm{~dB} Z$ when using the additional information provided by the Mont Vial radar. This discrepancy can greatly impact QPE values, which are critically important for watershed management as well as flash-flood forecasting, in general, and particularly important for southeast France.

In addition to improved reflectivity measurements, the RHYTMME radars can help resolve low-level wind flow within southeast France, where topography ranges from sea level to above $3000 \mathrm{~m}$ MSL, sometimes within a distance of only $20 \mathrm{~km}$. With such sharp increases in terrain, the spacing between ARAMIS radars is insufficient in many areas to retrieve data below $2-3 \mathrm{~km}$ above ground level. In Fig. 7, a vertical cross section shows the change in terrain from sea level toward the Alps, and the corresponding vertical velocity and overlaid reflectivity during the event of 25 October 2011 at 0230 UTC. Large regions of near-ground coverage gaps within Fig. 7a show the discrepancies in ARAMIS coverage. Figure 7b shows the additional wind field data that are retrieved when including the Mont Vial radar underlining the importance of the RHYTMME radar network.

The second precipitation event of 20 May 2012 took place after the Mont Maurel radar began operation; and therefore these data were added to the multipleDoppler syntheses. However, since the radar is situated at a height of $1773 \mathrm{~m} \mathrm{MSL}$, it is necessary to assess multipleDoppler analyses at or above $2 \mathrm{~km}$ MSL. Therefore, Fig. 8 shows the retrieved wind field for the ARAMIS radars at 2100 UTC (Fig. 8a), 2200 UTC (Fig. 8c), and 2300 UTC (Fig. 8e) for $2.5 \mathrm{~km}$ MSL. In addition, Figs. 8b, $8 \mathrm{~d}$, and $8 \mathrm{f}$ show the benefits that both Mont Maurel and Mont Vial radar data provide to the multiple-Doppler syntheses at the same respective times. It is clear that with five radars in total, a definitive advantage in the reconstruction of the wind field and reflectivity exists. Specifically, offshore wind vectors within the Gulf of Genoa (Fig. 8; $x>200, y>100$ ) are retrieved from Mont Vial data, while the addition of Mont Maurel data provides wind field data northwest of Mont Vial, within the southern Alps; both regions inaccessible by the ARAMIS radar network. Southeasterly winds over the Gulf of Genoa do not experience a significant change in direction nor intensity as they approach the extreme southeast coast of France. This is in contrast to winds within the Gulf of Lyon, which, upon reaching the coast, back sharply from a southwesterly to southeasterly direction.

\section{c. Orographic precipitation implications}

Orographic precipitation stability metrics presented previously in the literature (discussed above) were used to assess the nature of the wind flow for both case studies near mountainous terrain. Improved and expanded wind fields retrieved from a combination of the ARAMIS and 
(a)

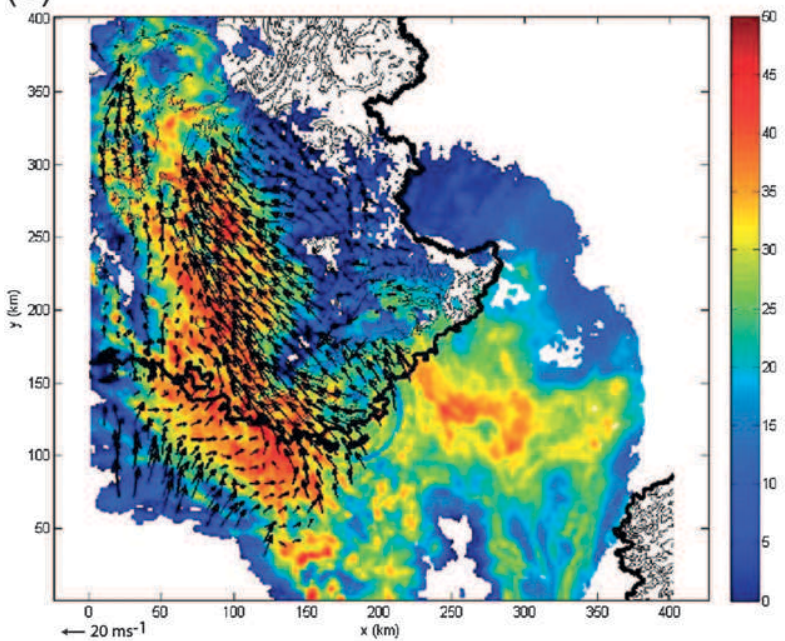

(c)

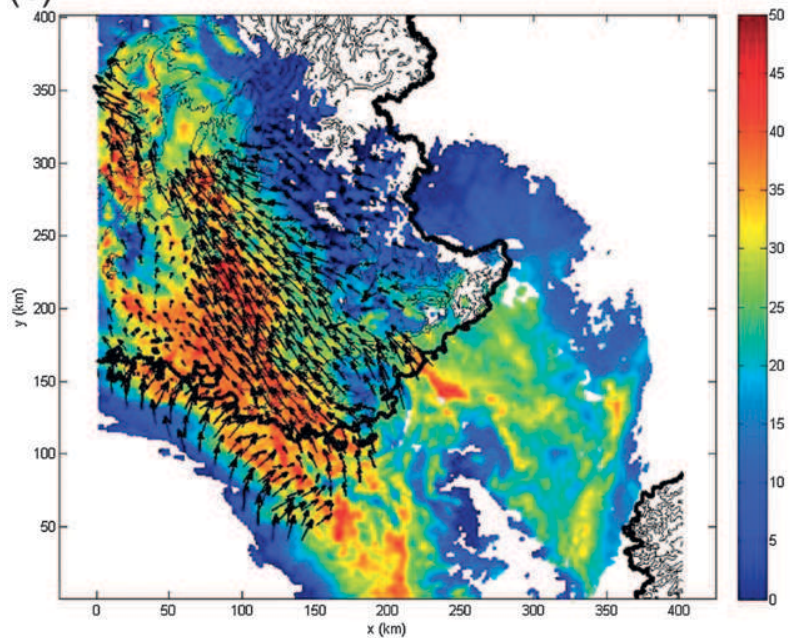

(e)

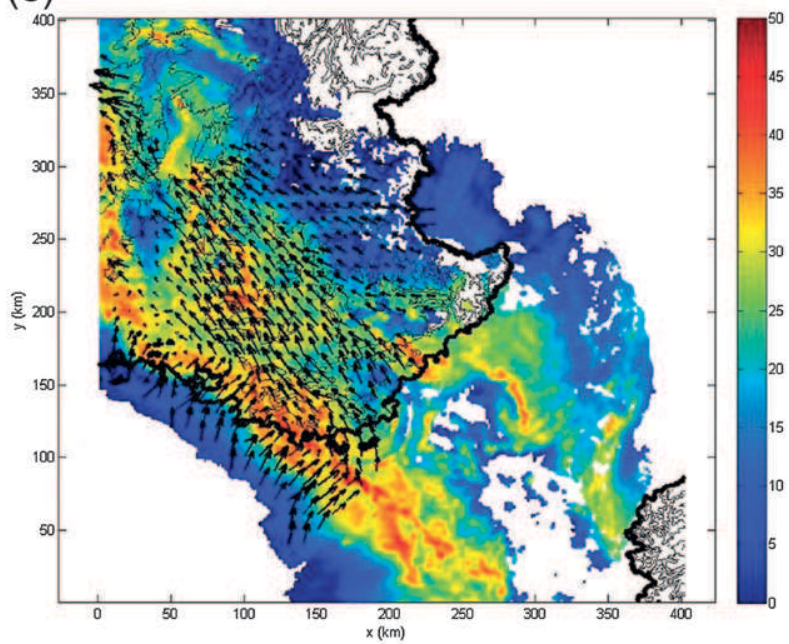

(b)

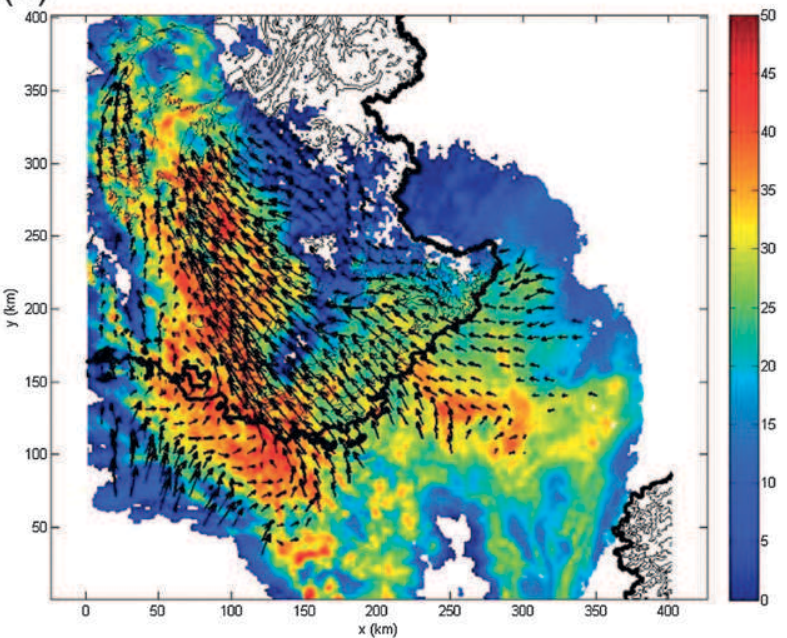

(d)

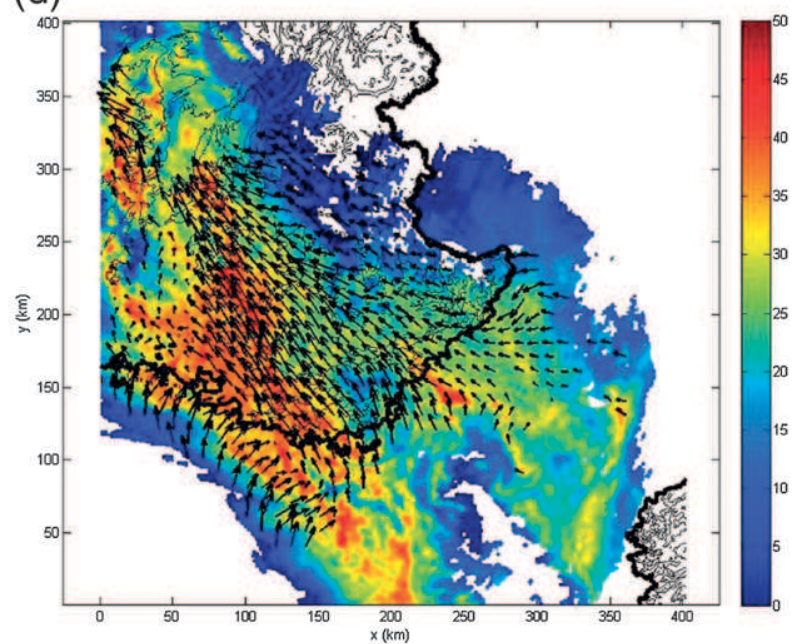

(f)

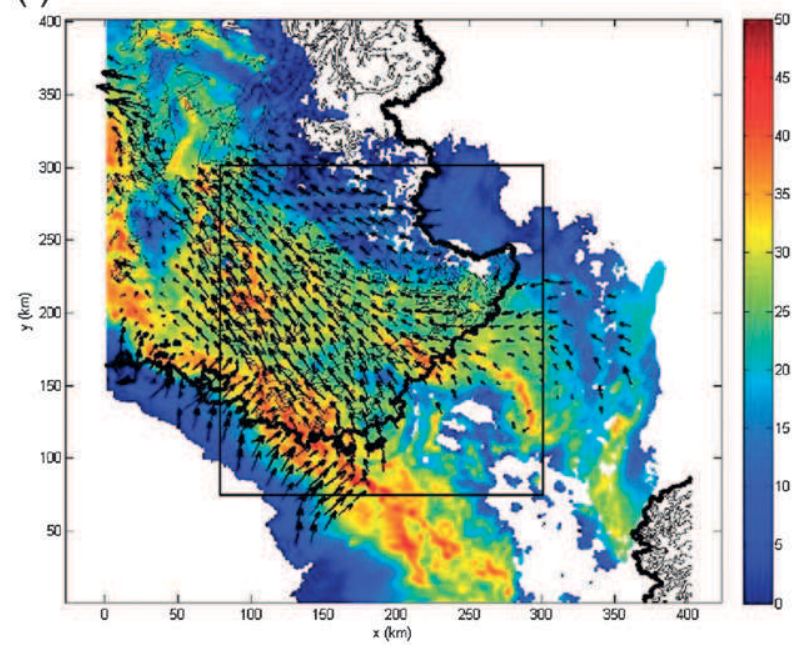

FIG. 8. As in Fig. 5, but for 20 May 2012 at (a),(b) 2100, (c),(d) 2200, and (e),(f) 2300 UTC for $2.5 \mathrm{~km}$ MSL and (right) with the addition of Mont Vial and Mont Maurel radars. Black box in (f) indicates location of Fig. 9. 
RHYTMME networks allowed for interpretation of these results adjacent to orography in regions previously inaccessible by the ARAMIS network. European Centre for Medium-Range Weather Forecasts Interim Re-Analysis (ERA-Interim) data were utilized to quantitatively assess these findings, in relation to low-level stability and terrain-blocking effects.

For the 25 October 2011 case, the 12-h 25 October 2011 surface-based CAPE forecast from these data shows a large region of greater than $700 \mathrm{~J} \mathrm{~kg}^{-1}$ extending from $3^{\circ}$ to $13^{\circ} \mathrm{N}$ and from $37^{\circ}$ to $44^{\circ} \mathrm{E}$, constituting a majority of the western Mediterranean. In addition, values greater than $1200 \mathrm{~J} \mathrm{~kg}^{-1}$ (with a maximum of $1700 \mathrm{~J} \mathrm{~kg}^{-1}$ ) were forecast between $38.5^{\circ}$ and $41^{\circ} \mathrm{N}$ and $4.5^{\circ}$ and $8.25^{\circ} \mathrm{E}$, just south of the Gulf of Lyon, the region from which air was later advected northward by the approaching synoptic system.

Vertical profiles of low-level temperature and mixing ratio from 0000 UTC 25 October 2011 ERA-Interim reanalysis data were also calculated for a location upstream of the southerly flow impacting the southern Alps. The virtual temperature lapse rate within the lowest $2 \mathrm{~km}$ for a location south of Marseille $\left(42.5^{\circ} \mathrm{N}, 5^{\circ} \mathrm{E}\right)$ was $9.5 \times 10^{-3}{ }^{\circ} \mathrm{C} \mathrm{m}^{-1}$, slightly less than the dry-adiabatic lapse rate. The corresponding squared moist BruntVäisälä frequency, defined as $\left(g / \bar{\theta}_{v}\right)\left(\partial \theta_{v} / \partial z\right)$ (Emanuel 1994), was $\sim 1.6 \times 10^{-3} \mathrm{~s}^{-1}$. These results indicate a weakly stable low-level air mass. However, the advection of surface-based CAPE into the region, combined with onshore flow velocities approaching $20 \mathrm{~m} \mathrm{~s}^{-1}$ at $1.5 \mathrm{~km}$ MSL (and exceeding this value at $3.0 \mathrm{~km} \mathrm{MSL}$ ) helped overcome the weak low-level stability, producing unblocked flow. Airflow was able to ascend the southern Alps, producing uniform precipitation over a large portion of the domain with reflectivity values above $30 \mathrm{dBZ}$ in most places onshore and above the mountains. The onshore flow identified off the coast of extreme southeast France (Figs. 6b,d,f) also shows no major change in magnitude or direction as it interacts with the mountains; a conclusion that would have otherwise been impossible to reach without the addition of the Mont Vial radar.

The uniform southerly flow over varying terrain indicates that air is able to traverse the mountainous regions of southern France in this case. To quantify the nature of this ascent, the moist Froude number is used $\left[U /\left(N_{w} H\right)\right]$, where $U$ is the wind speed perpendicular to the relief, $N_{w}$ is the squared moist Brunt-Väisälä frequency, and $H$ is the height of the relief (Chen and Lin 2005). Using the orientation of the southern Alps east of the Rhone River as an example, the terrain gradient follows a line roughly from $135^{\circ}$ to $315^{\circ}$. Wind vectors seen in Figs. 5 and 6 exhibit southerly flow. Therefore, the wind component perpendicular to the general orientation of the southern Alps in this region is around
$70 \%$ of the total flow magnitude at $1.5 \mathrm{~km}$ MSL. With a $70 \%$ scaling of the wind intensity, a Froude number of 1.76 is found using the wind speed and blocking terrain at the same height (along the escarpment of the southern Alps). A Froude number of this value supports the conclusion of unblocked flow.

When analyzing the 20 May 2011 case, the difference between offshore and onshore wind flow was of particular interest. Southwesterly flow (at times $>20 \mathrm{~m} \mathrm{~s}^{-1}$ ) in the Gulf of Lyon weakens and becomes southeasterly as it reaches the coast. Given the rough orientation of the southern Alps east of the Rhone River as described above, and the $320^{\circ}$ wind seen in the same region, the intensity of the wind flow perpendicular to the relief represents only $10 \%$ of the magnitude of the wind. On a broader scale, overall surface-based CAPE from the 6-h ERA-Interim reanalysis forecast for 1800 UTC does show some small pockets of CAPE over $1000 \mathrm{~J} \mathrm{~kg}^{-1}$ within the Gulf of Lyon; however, an average of only $154 \mathrm{~J} \mathrm{~kg}^{-1}$ is found within the same region, which contained a domain-wide $700 \mathrm{~J} \mathrm{~kg}^{-1}$ or above for the 25 October 2011 case. Using the same location south of Marseille as in the previous case, the 1800 UTC ETA-Interim reanalysis virtual temperature lapse rate within the lowest $2 \mathrm{~km}$ was $5.3 \times$ $10^{-3}{ }^{\circ} \mathrm{C} \mathrm{m}^{-1}$. The resulting squared Brunt-Väisälä frequency is then $\sim 10^{-2} \mathrm{~s}^{-1}$, an order of magnitude larger than during 25 October 2011, indicating a more stable air mass than in the previous case. Finally, using the $10 \%$ scaling of the wind flow to retrieve the wind perpendicular to the mountains, the Froude number east of the Rhone River is 0.2. These findings suggest that the lowlevel flow in this region was blocked by the mountains.

The resulting convergence identified in the multipleDoppler syntheses, collocated with the blocked flow, corresponds well with regions of high reflectivity, particularly south of the Rhone River flood plain (i.e., Fig. 8; $x=80, y=150$ ). Convergence likely aided in the development of convective updrafts and high rain rates in this region. In contrast, precipitation intensity decreases significantly over the southern Alps (Fig. 8; $x>$ $150, y>200$ ), another potential sign of terrain blockage. The overall low-level flow structure and resulting distribution of precipitation during the 20 May 2012 event differs substantially from the 25 October 2011 case, where reflectivity and wind flow were more or less uniform throughout the domain. Therefore, the differences in wind flow and precipitation distribution are likely a result of differences in the strength of the onshore flow, stability, and the resulting interaction with the terrain.

\section{d. Independent RHYTMME dual-Doppler analysis}

A final analysis was conducted to assess the multipleDoppler data quality of the two RHYTMME radars, 
(a)

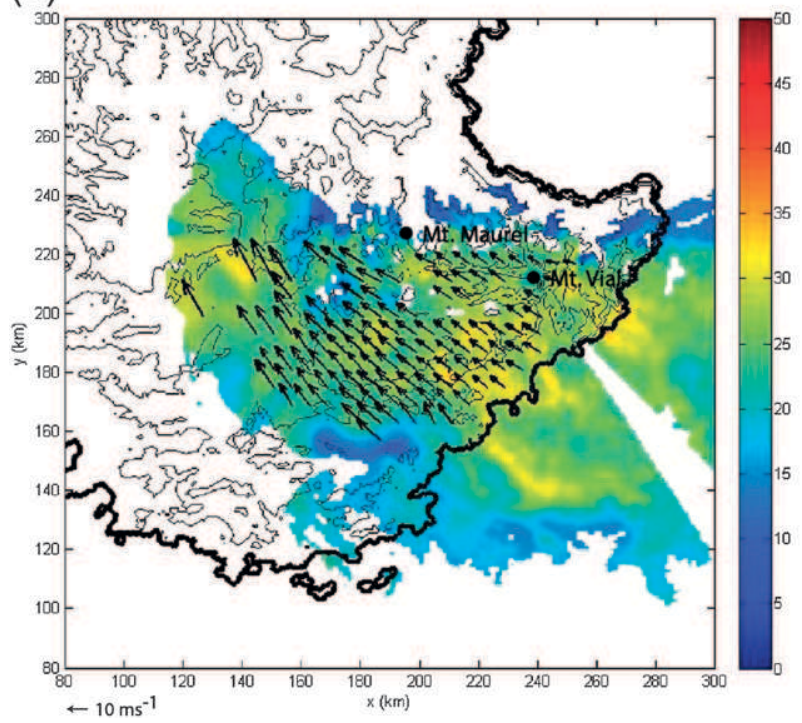

(b)

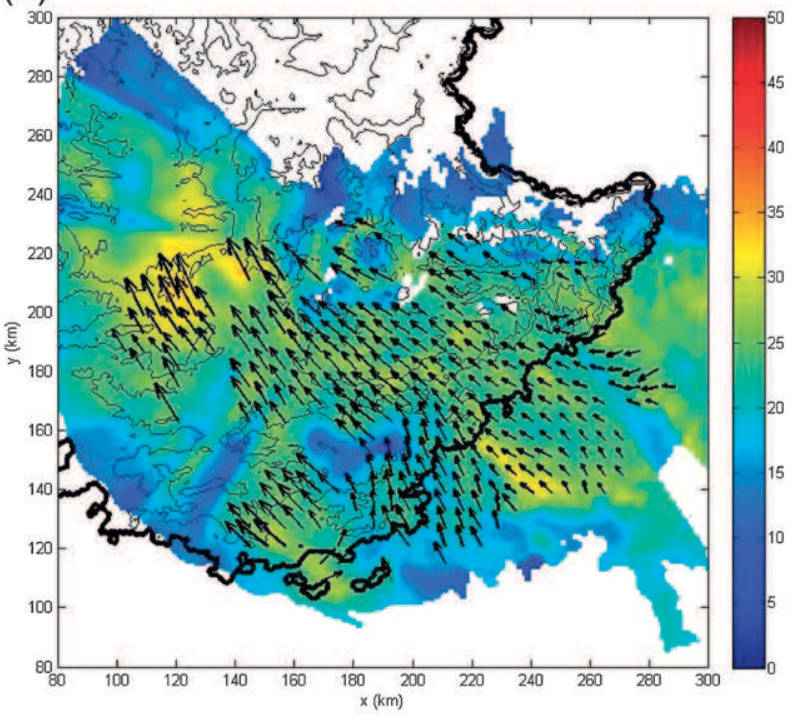

FIG. 9. Dual-Doppler syntheses for 20 May 2012 at 2200 UTC for (a) 2 and (b) $2.5 \mathrm{~km}$ MSL for the Mont Vial and Mont Maurel radars showing 2D wind vectors (black; every third vector), reflectivity (color; dBZ), and terrain contours (gray). The locations of Mont Vial and Mont Maurel are indicated in (a).

independent of the ARAMIS network. Figure 9 shows dual-Doppler wind field retrievals between the two X-band radars, Mont Vial and Mont Maurel, for 20 May 2012 at 2200 UTC for $2 \mathrm{~km}$ MSL (Fig. 9a) and $2.5 \mathrm{~km}$ MSL (Fig. 9b). These results show that the retrieval of a coherent wind field is possible over mountainous terrain when using only the new RHYTMME radars. These syntheses help justify the accuracy of the radars and their ability to contribute to multiple-Doppler syntheses with the ARAMIS radars. Note, however, that the dualDoppler retrieval area seen in Fig. 9 is quite limited, showing that the improved coverage resulting from the use of gap-filling radars is primarily due to the combination of ARAMIS and RHYTMME radial velocity data.

\section{Conclusions}

The current French ARAMIS radar network lacks sufficient coverage in the high-terrain regions of southeast France, areas that are particularly susceptible to dangerous flash flooding. The RHYTMME project was therefore created to improve radar coverage in the southern Alps and to better understand and forecast the evolution of future high-precipitation events. The supplementary network will consist of four new X-band radars by 2013, greatly increasing the real-time, multiple-Doppler coverage over a broad region of both high terrain and the Mediterranean Sea. The ability to accurately retrieve three-dimensional wind fields, in particular upstream of complex orography within this region, is a key to achieving this goal.
This study illustrates the invaluable addition that the gap-filling Mont Vial and Mont Maurel radars provide. To exemplify these advantages, results are presented from multiple-Doppler syntheses from 25 October 2011 and 20 May 2012, as two synoptic systems traversed southeast France. Syntheses were produced using the ARAMIS network radars alone, and then including the newly installed RHYTMME-based Mont Vial radar for the 25 October 2011 case, as well as both Mont Maurel and Mont Vial data for the 20 May 2012 case. The coverage is shown to be limited in extreme southeastern France using only the ARAMIS radars. In addition, it is shown that multiple-Doppler retrieval of three-dimensional winds over the Mediterranean and low levels over mountainous terrain is impossible without the aid of the gap-filling RHYTMME radars. Finally, dual-Doppler analyses using solely the Mont Vial and Mont Maurel radars verify the accuracy of wind retrieval from the RHYTMME radars over the southern Alps.

Further analysis of the 25 October 2011 case study indicates that onshore flow was relatively unaffected by the complex terrain of southeast France due to low-level instability with uniform wind and reflectivity fields found throughout the domain. In addition, the ascent of air over the southern Alps indicates a correlation between terrain and stronger reflectivity as updrafts are generated along regions of sharp changes in relief. Ascent continues over the mountains, and regions of higher reflectivity exist over elevated terrain when compared with lower-elevation regions. In contrast, the second case 
study from 20 May 2012 indicates blocked low-level flow east of the Rhone River as onshore winds from the Gulf of Lyon are redirected when interacting with the coast and terrain of southeast France. Observed regions of high reflectivity were likely related to convergence, and the resulting ascent of blocked flow along the periphery of the mountains, while over higher terrain, much lower values of reflectivity were present. These two case studies exemplify the importance of gap-filling radars within a broader radar network to provide increased coverage and data accuracy.

The use of multiple-Doppler wind field data in numerical simulations represents a promising area of future research. Data from real-time, multiple-Doppler wind syntheses can be incorporated into model forecasts at initialization to assess the potential benefit they may provide. Specifically, data can be incorporated into research-based models, such as the Applications de la Recherche à Mésoéchelle model (AROME; Seity et al. 2011), to assess potential improvements in forecasting accuracy of rainfall amount and location, wind speed and direction, and the overall timing of high-precipitation events.

Acknowledgments. The authors thank the European Union, the Provence-Alpes-Côte d'Azur Region, and the French Ministry of Ecology, Energy, Sustainable Development and Sea for cofinancing the RHYTMME project. Thanks are given to Pierre Tabary, Fadela Kabeche, Hassan Al-Sakka, Abdel-Amin Boumahmoud, Clotilde Augros, and Beatrice Fradon for their help with data acquisition and processing during this research.

\section{REFERENCES}

Al-Sakka, H., M. Buguet, S. Frasier, K. Bouyer, B. Fradon, A.-A Boumahmoud, and P. Tabary, 2012: Hydrometeor classification using polarimetric radars: Intercomparison and hail detection. Proc. Seventh European Conf. on Radar in Meteorology and Hydrology, Toulouse, France, EUMETSAT-WMO, 2.5. [Available online at http://www.meteo.fr/cic/meetings/2012/ ERAD/extended_abs/MIC_004_ext_abs.pdf.]

Augros, C., and P. Tabary, 2009: Improvements of the French operational triple-PRT Doppler scheme. Preprints, 34th Conf. on Radar Meteorology, Williamsburg, VA, Amer. Meteor. Soc., P5.5. [Available online at https://ams.confex.com/ams/ pdfpapers/155529.pdf.]

Bougeault, P., and Coauthors, 2001: The MAP special observing period. Bull. Amer. Meteor. Soc., 82, 433-462.

Bousquet, O., and M. Chong, 1998: A multiple-Doppler synthesis and continuity adjustment technique (MUSCAT) to recover wind components from Doppler radar measurements. J. Atmos. Oceanic Technol., 15, 343-359.

- and P. Tabary, 2013: Development of a nationwide real-time 3-D wind and reflectivity radar composite in France. Quart. J. Roy. Meteor. Soc., doi:10.1002/qj.2163, in press. $\longrightarrow,-$, and J. Parent-du-Châtelet, 2007: On the value of operationally synthesized multiple-Doppler wind fields. Geophys. Res. Lett., 34, L22813, doi:10.1029/2007GL030464.

— , T. Montmerle, and P. Tabary, 2008a: Using operationally synthesized multiple-Doppler winds for high resolution horizontal wind forecast verification. Geophys. Res. Lett., 35, L10803, doi:10.1029/2008GL33975.

— multiple-Doppler wind retrieval inferred from long-range radial velocity measurements. J. Appl. Meteor. Climatol., 47, 2929-2945.

Caumont, O., V. Ducrocq, E. Wattrelot, G. Jaubert, and S. PradierVabre, 2010: 1D+3DVar assimilation of radar reflectivity data: A proof of concept. Tellus, 62A, 173-187.

Chen, S., and Y. Lin, 2005: Effects of moist Froude number and CAPE on a conditionally unstable flow over a mesoscale mountain ridge. J. Atmos. Sci., 62, 331-350.

Cressman, G. P., 1959: An operational objective analysis system. Mon. Wea. Rev., 87, 367-374.

Dixon, M., and G. Wiener, 1993: TITAN: Thunderstorm Identification, Tracking, Analysis, and Nowcasting-A radar-based methodology. J. Atmos. Oceanic Technol., 10, 785-797.

Emanuel, K. A., 1994: Atmospheric Convection. Oxford University Press, $580 \mathrm{pp}$

Gabella, and Coauthors, 2012: A network of portable, low-cost X band radars. Doppler Radar Observations-Weather Radar, Wind Profiler, Ionospheric Radar, and Other Advanced Applications, J. Bech and J. L. Chau, Eds., InTech, 175-202.

Germann, U., and I. Zawadzki, 2002: Scale-dependence of the predictability of precipitation from continental radar images. Part I: Description of the methodology. Mon. Wea. Rev., 130, 2859-2873.

—, G. Galli, M. Boscacci, and M. Bolliger, 2006: Precipitation measurement in a mountainous region. Quart. J. Roy. Meteor. Soc., 132, 1669-1692.

Glickman, T. S., Ed., 2000: Glossary of Meteorology. 2nd ed. Amer. Meteor. Soc., 850 pp.

Gourley, J. J., P. Tabary, and J. Parent du Chatelet, 2007: A fuzzy logic algorithm for the separation of precipitating from nonprecipitating echoes using polarimetric radar observations. J. Atmos. Oceanic Technol., 24, 1439-1451.

Jorgensen, D. P., T. R. Shepherd, and A. S. Goldstein, 2000: A dual-pulse repetition frequency scheme for mitigating velocity ambiguities of the NOAA P-3 airborne Doppler radar. J. Atmos. Oceanic Technol., 17, 585-594.

Maddox, R. A., J. Zhang, J. J. Gourley, and K. W. Howard, 2002: Weather radar coverage over the contiguous United States. Wea. Forecasting, 17, 927-934.

Maki, M., and Coauthors, 2010: X-band polarimetric radar networks in urban areas. Proc. Sixth European Conf. on Radar in Meteorology and Hydrology, Sibiu, Romania, EUMETSATWMO, P14.9. [Available online at http://www.erad2010.org/pdf/ POSTER/Thursday/02_Xband/11_ERAD2010_0354_extended. pdf.]

McLaughlin, D., and Coauthors, 2009: Short-wavelength technology and the potential for distributed networks of small radar systems. Bull. Amer. Meteor. Soc., 90, 1797-1817.

Medina, S., and R. A. Houze Jr., 2003: Air motions and precipitation growth in Alpine storms. Quart. J. Roy. Meteor. Soc., 129, 345-371.

, B. F. Smull, R. A. Houze Jr., and M. Steiner, 2005: Crossbarrier flow during orographic precipitation events: Results from MAP and IMPROVE. J. Atmos. Sci., 62, 35803598 
Montmerle, T., and C. Faccani, 2009: Mesoscale assimilation of radial velocities from Doppler radars in a preoperational network. Mon. Wea. Rev., 137, 1939-1953.

Panziera, L., and U. Germann, 2010: The relation between airflow and orographic precipitation on the southern side of the Alps as revealed by weather radar. Quart. J. Roy. Meteor. Soc., 136, 222-238.

- — - M. Gabella, and P. V. Mandapaka, 2011: NORANowcasting of Orographic Rainfall by means of Analogues. Quart. J. Roy. Meteor. Soc., 137, 2106-2123.

Philips, B., V. Chandrasekar, J. Brotzge, M. Zink, H. Rodriguez, C. League, and W. Diaz, 2010: Performance of the CASA radar network during the May 13, 2009 Anadarko tornado. Preprints, 15th Symp. on Meteorological Observation and Instrumentation, Atlanta, GA, Amer. Meteor. Soc., 9.3. [Available online at https://ams.confex.com/ams/pdfpapers/ 165864.pdf.]

Rotunno, R., and R. A. Houze Jr., 2007: Lessons on orographic precipitation from the Mesoscale Alpine Programme. Quart. J. Roy. Meteor. Soc., 133, 811-830.
Schultz, D. M., and Coauthors, 2002: Understanding Utah winter storms: The Intermountain Precipitation Experiment. Bull. Amer. Meteor. Soc., 83, 189-210.

Seity, Y., P. Brousseau, S. Malardel, G. Hello, P. Bénard, F. Bouttier, C. Lac, and V. Masson, 2011: The AROME-France convective-scale operational model. Mon. Wea. Rev., 139, 976-991.

Stoelinga, M. T., and Coauthors, 2003: Improvement of Microphysical Parameterizations Observational Verification Experiments (IMPROVE). Bull. Amer. Meteor. Soc., 84, 1807-1826.

Tabary, P., F. Guibert, L. Perier, and J. Parent-du-Chatelet, 2006: An operational triple-PRT Doppler scheme for the French radar network. J. Atmos. Oceanic Technol., 23, 16451656.

Westrelin, S., P. Mériaux, P. Tabary, and Y. Aubert, 2012: RHYTMME Project: Risk management based on a radar network. Proc. European Conf. on Radar in Meteorology and Hydrology, Toulouse, France, EUMETSAT-WMO, 11.5. [Available online at http://www.meteo.fr/cic/meetings/2012/ ERAD/short_abs/HS_404_sh_abs.pdf.] 